\title{
An Analysis of Hate Speech among Armenian Facebook Users
}


Abstract

Social media networking websites have become platforms where users can not only share their photos, moments of happiness, success stories and best practices, but can also voice their criticism, discontent and negative emotions. It is interesting to follow how something that starts as a mere disagreement or conflict over clashing interests or values can develop into a hateful exchange on Facebook that targets social media users based on their gender, religious belonging, ethnicity, sexual orientation, political convictions etc.

The present research explores how hateful posts and comments can start among Facebook users, and studies the language means employed in their design.

The factual material was retrieved from more than ten open Facebook pages managed by popular Armenian figures, such as media experts, journalists, politicians and bloggers, in the period 2018-2020.

The analysis of hate speech samples extracted from these sources shows that hate speech can find its explicit and implicit reflection in the online communication of Armenian Facebook users, and can be characterised by contextual markers such as invisibility, incitement to violence, invectiveness and immediacy. The language analysis of the posts and comments comprising hate speech has helped to identify language features of hateful comments including informal tone, use of passive voice, abusive and derogatory words, rhetorical or indirectly formed questions, generalisations and labelling. 


\section{Introduction}

The arrival and unexpected rise of information technologies have led many social media users to consider using the opportunity to publicly voice their opinions, preferences and assessments. This is not only deemed a curse, but also a sudden gift for expressing their dispositions, prejudices and criticism in public - however harsh, unreasonable and unfair these might be. If, in the past, writing and reporting news stories were the privilege of reporters alone, the average social media user today can assume the role of writer, commentator, publisher, critic and even expert.

It comes as no surprise that hate speech, the study of which has mostly been confined to the domains of law and politics over the past two decades, has shifted into the focus of applied linguists and discourse analysts, whose studies mostly centre on analysing instances of discriminatory discourse in the context of racist comments and remarks (see van Dijk 1984, 1991; Wodak 2009).

The present paper is an attempt to study the development of hateful comments and posts among Armenian users on Facebook social networking website, bearing in mind the contextual and language markers that define them.

\section{Literature review}

\subsection{Defining and identifying hate speech}

Despite the fact that the term 'hate speech' is widely used in a range of contexts, it does not yet have a generally recognised definition, most probably because of its universal use. It might be relatively easy to identify an instance of hate speech in online communication, but when it comes to defining it, there are no precise criteria. If a Gen $Z$ representative decides to Google 'hate speech' today instead of looking it up in a reference book, the definition they will most likely come across is the one that refers to hate speech as 'abusive or threatening speech or writing that expresses prejudice against a particular group, especially on the basis of race, religion, or sexual orientation'. ${ }^{1}$

For dictionary lovers, the Dictionary of Etymology registers that the use of 'hate speech' as a term was attested as early as 1990 - the end of the twentieth century. It obviously owes its origin to 'hate crime', a term that was first registered back in $1988^{2}$, which is used to describe an offence or a series of offences that usually involve violence committed against someone because of their religion or race. ${ }^{3}$

The Cambridge English Dictionary defines hate speech as 'public speech that expresses hate or encourages violence towards a person or group based on something as race, religion, sex or sexual orientation'. ${ }^{4}$ The Merriam-Webster Dictionary, which claims to be the most trusted online dictionary, registers hate speech as 'speech expressing hatred of a particular group of people'. ${ }^{5}$

It is also interesting to note that throughout time, many definitions of hate speech have been formulated to address emerging discriminatory practices or to respond to instances of offensive language. For example, Jeremy Waldron in his paper 'The Harm in Hate Speech'

\footnotetext{
${ }^{1}$ From Oxford Dictionary https://www.lexico.com/en/definition/hate speech, Accessed on 1 May 2020.

2 From Dictionary of Etymology" https://www.etymonline.com/word/hate, Accessed on 1 May 2020.

${ }^{3}$ From Cambridge English Dictionary https://dictionary.cambridge.org/dictionary/english/hate-crime, Accessed on 26 April 2020.

${ }^{4}$ Ibid.

${ }^{5}$ From Merriam-Webster Dictionary https://www.merriam-webster.com/dictionary/hate\%20speech, Accessed on 25 April 2020.
} 
describes hate speech as an assault on someone's dignity in an attempt to denigrate or eliminate their social standing. ${ }^{6}$

In their analysis of news website comments, K. Erjavec and M. P. Kovačič compare hate speech to a new kind of war, describing it as any expression that is directed against people on the basis of their race, ethnicity, origin, religion, gender, age, physical condition, disability, sexual orientation, political conviction etc. ${ }^{7}$

The aforementioned definitions imply that hate speech can at times target groups of people on the basis of certain shared characteristics, as well as individuals who represent such groups. In this respect, researchers from the University of California suggest distinguishing between directed and generalised hate speech. If the former is directed at a specific individual, the latter targets a group or class of people. ${ }^{8}$ Generalised hate speech is thus described as emphasising 'they' and not 'we', and is characterised by frequent use of third personal pronouns, whereas directed hate speech sounds more informal, social and at the same time more aggressive.

\subsection{Recognising hate speech}

As hate speech definitions are so diverse, it can sometimes be very difficult to assess whether a given comment is merely an offensive remark or an instance of hate speech. My observations ${ }^{9}$ show that a micro-aggressive remark or a simple offence in a Facebook post or comment can very often be erroneously perceived and labelled as a manifestation of hate speech by the users themselves because of the harsh criticism or derogatory words it portrays. At the same time, an analysis of the key features defining hate speech shows that a nasty comment about an individual or an insult may not be enough to be considered hate speech. However ambiguous and generic the definitions of hate speech may be, they all agree on something that almost all hate messages tend to include, which is incitement to hostility or violence.

It would appear to be easier to identify explicit hate speech messages online. In their work, Silva and Mondal $^{10}$ suggest using a sample sentence structure to detect hate speech in social media, in the event that the researcher or reader does not have sufficient information on the key hate words or targets. The core of their idea is that: 'If some user posts about their hateful emotions in a post, e.g. "I really hate black people", then there is little ambiguity that it is an example of hate speech.' In this respect, the sentence structure can be leveraged to effectively detect instances of hate speech. The following sentence template has been developed to ease the search for hate speech samples in social media:

$$
\text { I }<\text { intensity }><\text { user intent }><\text { hate target }>
$$

As we can see, the subject ' $\mathrm{I}$ ' refers to the social media user who is communicating their personal emotions. The verb that follows it signals the user's negative intent or indicates how he or she feels. This intent is usually expressed by verbs such as 'hate', 'loathe', 'despise' etc. Finally, the hate target implies the recipient of hate speech. This strategy might not serve to

\footnotetext{
${ }^{6}$ See Waldron, J. (2012) for more information on hate speech http://www.iconnectblog.com/2013/02/book-reviewjeremy-waldrons-the-harm-in-hate-speech

${ }^{7}$ See Karmen Erjavec \& Melita Poler Kovačič (2012) "You Don't Understand, This is a New War!" Analysis of Hate Speech in News Web Sites' Comments, Mass Communication and Society, 15:6, 899920, DOI: 10.1080/15205436.2011.619679

${ }^{8}$ See ElSherief, Mai \& Kulkarni, Vivek \& Nguyen, Dana \& Wang, William \& Belding, Elizabeth. (2018). Hate Lingo: A Target-based Linguistic Analysis of Hate Speech in Social Media. https://arxiv.org/pdf/1804.04257.pdf

${ }^{9}$ See Bekaryan, L. (2019) Ways of Expressing Hate Speech in the Social Media in Armenia. Yerevan: Misma LTD.

${ }^{10}$ See Silva, Leandro \& Mondal, Mainack \& Correa, Denzil \& Benevenuto, Fabrício \& Weber, Ingmar. (2016). Analyzing the Targets of Hate in Online Social Media.

https://www.researchgate.net/publication/301837126 Analyzing the Targets of Hate in Online Social Media
} 
identify all existing hate speech in social media, but it may facilitate researchers' online quest for examples.

At the same time, there are ongoing debates about whether any kind of hate speech can inspire violence. In this respect, it is worth considering Susan Benesch's view, who considers hate speech to be a broad and at the same time ambiguous category. Benesch argues that no one is born to hate or incite others to commit violence, as hatred is not an inborn quality but something that can be nurtured through a particular kind of rhetoric and certain vocabulary used by influential people to denigrate others. In her definition of speech or any form of expression that can increase the risk of the audience committing violence against members of another group, Benesch introduces a new term, 'dangerous speech'. It is interesting to note that Benesch's definition is related to the 'risk' of violence, rather than cause of it. ${ }^{11}$ She also claims that dangerous speech can only target groups of people, rather than individuals, and threaten their integrity by the assertion of violent attacks towards them.

Benesch lists five variables that can be used to identify hate speech, at least two of which must be present for a message to be recognised as dangerous or hate speech. Among these variables, Benesch identifies the degree of the hate speaker's influence over the audience; the fears cultivated by the speaker; the speech act that can be understood as a call to violence; the social and historical context in which the hate speech is generated; and a means of dissemination that is influential in itself, for example whether it is the only or the main source of news for the relevant audience. ${ }^{12}$

In the present research, hate speech is studied in the context of public Facebook posts and comments, and is defined as any abusive discourse that can incite violence, hatred or discrimination against a specific group of people sharing certain characteristics, which may include gender, class, ethnicity, religion or occupation, or an individual representing one of these groups. At the same time, I accept Susan Benesch's view on the ambiguity of the term 'hate speech' itself and therefore use expressions such as 'hate comments' or 'hate posts' interchangeably to describe the hostile language targeting a certain group or an individual representing it. The initiators of hate speech in the paper are referred to as hate speakers or hate writers.

\section{Research methodology}

The analysis in this study was performed by means of the combined application of contextual analysis and discourse analysis methods. The use of contextual analysis was helpful to assess the text within the context of its historical and cultural setting, and to evaluate the intensity of the generated Facebook post and/or comment, while taking into consideration factors such as the identity of the poster or the commentator; the historical setting on which the generated text comprising hate speech was based; and the level of influence the poster or the commentator has over their Facebook followers.

Conducting a discourse analysis was useful to identify the linguistic choices of the hate speakers; the vocabulary and the structures they tend to use when building their comments or posts; the tone of speech they use when targeting their message; and the impact of the presence of non-verbal communication cues in the message.

To analyse the language markers inherent in the hate speech samples written by Facebook users in Armenia, I studied more than ten Facebook pages with public access and managed by people that enjoy relative popularity in Armenia over a period of two years. Most of these are bloggers, writers, reporters and human rights activists, and the number of followers

\footnotetext{
${ }^{11}$ See Benesch, S. (2012) Dangerous Speech: A Proposal to Prevent Group Violence. World Policy Institute. http://worldpolicy.org/wp-content/uploads/2016/01/Dangerous-Speech-Guidelines-Benesch-January-2012.pdf $\frac{12}{12} \mathrm{Ibid}$
} 
ranges from five thousand to ten thousand, which is a solid figure for a country as small as Armenia.

All the hate posts and comments under study were initially generated in Armenian and the paper provides their verbatim translations.

\section{Analysis}

The study of hate speech posts or comments on the public pages of Armenian Facebook users showed cases where the public figures themselves initiated the hateful posts targeting certain groups. At the same time, there were also cases where the celebrities themselves became the recipient of hateful comments due to their adherence to a certain group or for advocating the rights of people representing a certain group.

As the scope of the present paper does not provide an opportunity to dwell on all fifty examples extracted from the Facebook pages of Armenian users, I will start by discussing the most common descriptors of hate messages posted by Armenian social media users and elaborate on the most interesting cases and examples. As my research is based on factual material in Armenian, I have provided the English translations of the analysed samples.

Online hate speech is obviously different from offline hate speech, as it unfolds in an entirely different medium, does not necessarily have to be synchronous timewise, and very often takes place between people who barely know each other or are complete strangers.

The analysis led to the identification of four main features of the selected online hate speech samples produced by Armenian users. I have decided to tentatively call these specific features the four 'i's of online hate communication. The first ' $i$ ' stands for invisibility, which relates to the anonymity of the user's identity. As we know, there is no law that can compel the social media user to post their comment or generate a post using their real identity. The absence of fear of being identified may encourage hate speakers to be as harsh as possible in their comments.

Research suggests that people are more inclined to use criticism when they are deprived of the opportunity to keep their antisocial behaviour in check and follow the social cues of their interlocutor. ${ }^{13}$ In this respect, it is interesting to note that users very often resort to adopting fake identities, and in this way seek detachment by establishing a kind of distance between themselves, the hate speaker and the recipient of the hateful message.

In psychology, this is known as the disinhibition effect, a term proposed by psychologist John Suler. Suler explains that people do not do or say things in cyberspace that they would actually do in real-time communication. They tend to openly express their personal problems, fears and secrets, and at the same time are not afraid of sharing their open criticism, anger or even hatred. ${ }^{14}$

To illustrate this, let us consider Example 1 that comprises a hate comment retrieved from Armenian journalist Zaruhi Mejlumyan's Facebook page.

\footnotetext{
${ }^{13}$ See Citron, D.K. (2014) Hate Crimes in Cyberspace. Cambridge: Harvard University Press.

${ }^{14}$ See Suler, J. (1996). The Psychology of Cyberspace. http://truecenterpublishing.com/psycyber/psycyber.html
} 


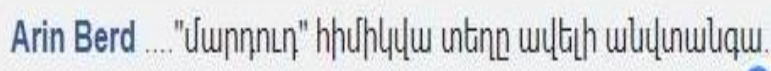

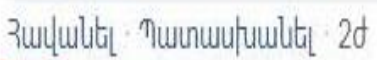

\section{English translation of the comment}

Your man is in a safer place now.

\section{Example $1^{15}$}

The comment was originally posted in Armenian, and if we consider this comment without knowing the circumstances under which it was generated, we can see nothing threatening or intimidating in its message. However, when we probe further into the historical background and context, we learn that Zaruhi Mejlumyan, the target of the comment, is an Armenian reporter and a human rights advocate who has been a long-time defender of the rights of people serving life imprisonment. Back in 2013, she married Mher Yenokyan, a 'life-termer', who is still serving in prison. When the couple failed to publicise their marriage, there was a barrage of criticism against Zaruhi in the media for a number of reasons, one of which being that she could not be 'forgiven' for having fallen in love with a man labelled 'a life-termer and 'a criminal'.

For more than ten years, Zaruhi has been trying to prove that Mher deserves pardon after having served twenty-five years in prison.

Zaruhi's husband, Mher Yenokyan, has been an unusual life-termer in the context of Armenia. A former major in medicine, he insisted on receiving education in prison (he decided to major in law to be able to acquit himself, as he put it), and later assumed the position of a prison correspondent for an Armenian media outlet. Mher never admitted to being guilty of the crime he was charged with. He was imprisoned at the age of 20 and sentenced to life imprisonment for killing his friend, who was his classmate. Throughout his service, he attempted escape from prison several times and has written a lot about injustice for those serving life imprisonment in Armenia.

One of the reasons why Mher was not pardoned was due to the many people who staged demonstrations in the streets, chanting that murderers like him cannot be pardoned and need to remain in prison. The family of the victim even hosted a press conference voicing their concerns over the possibility of having Mher released.

The social media user's identity in the first example is also worth some attention, as he is obviously not using his real name but that of a fortress, 'Arin Berd'. The name Arin Berd relates to Erebuni Fortress, a Urartian fortified city, which, literally translated from Armenian, means 'a fortress of blood'. A psychologist would probably try to find hidden implications even in the choice of name, one of the components of which is 'blood'. Having adopted this topographic name for his social media presence, the user obviously seeks to maintain invisibility by faking his identity. The dark image he has chosen for his Facebook account, with his cap concealing most of his face, supports this intention. At the same time, his adoption of a historical landmark of the country as a social media name may speak of his willingness to construct an online identity of himself as someone who represents historical

\footnotetext{
${ }^{15}$ From https://www.facebook.com/Mardaser Zaruhi Mejlumyan's Facebook page. Accessed on 17 January 2019.
} 
Armenia, does not welcome change and may defy unconventional decisions such as supporting a commuted sentence for a life-termer.

In his comment, 'Your man is in a safer place now', the user adopts an extremely informal tone through the use of an informal possessive pronoun / uunnnın/ ${ }^{16}$, despite the fact that he is addressing a woman he has not met and does not know. It is also interesting to note his choice of the word 'man' / uwnn/ rather than 'husband' /uunuuhi/, and the fact that he placed the word in inverted commas, as if questioning the validity of their marriage. Zaruhi, the recipient of the comment, reported it, obviously perceiving it as a threat to the safety and security of her husband.

The second ' $\mathrm{i}$ ' of hate speech is incitement to violence. With so much unfiltered information on the internet, users may feel encouraged to call to violence. This can be seen in Example 2 below, where one of the hate speakers calls for violence towards a famous Armenian film critic and translator, who is believed to promote LGBT values in Armenia. The word-for-word translation of his comment is: 'If it's true, his throat should certainly be slit'.

The speaker posted his comment instantaneously on a Facebook post that did not state the film critic's involvement in the promotion of LGBT values. The post simply reiterated an accusation voiced by a TV viewer that he might support the LGBT community simply because he decided to translate 'Tropic of Cancer' ${ }^{17}$ by Henry Miller into Armenian. This implies that the comment-writer might not have read the full post and instead fallen victim to key provocative words in the heading: 'immoral', 'sexual issues', and 'perverts'.

Edo Soghomonyan commented on news.am.

1 hout ago ids

ete tenc ban ka viz ktrel anxos

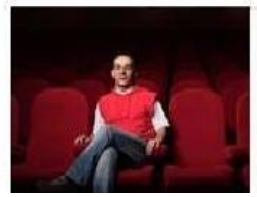

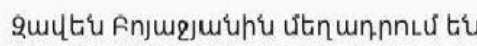

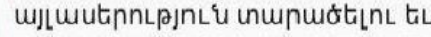

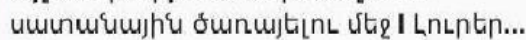

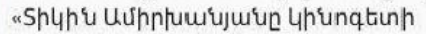

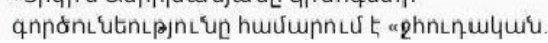

\section{English translation of the comment}

If it's true, his throat should certainly be slit.

\section{Example $2^{18}$}

Language-wise, we can see the user inciting the Facebook audience to violence through a command made in passive voice ('his throat should be slit'). This choice of structure speaks of his intention to be vague about who will assume that responsibility, while his use of the modal verb 'should' signals the necessity of the action. The use of the adverb 'certainly' /anxos/ supports the hostility of the phrase.

\footnotetext{
${ }^{16}$ The difference is obvious in Armenian where we have two types of the personal pronoun 'you', the difference in use between which depends on the formality of the setting and the level of familiarity between the speakers.

17 'Tropic of Cancer', a novel by Henry Miller, was first published in 1934. It is mostly known for being the subject of much controversy because of the obscene and pornographic scenes it portrays. The Armenian translation of the novel was published in 2014.

${ }^{18}$ From https://www.facebook.com/hatespeecharmenia/. Accessed on 2 November 2018.
} 
The fact that the user obviously posted his comment without having read the post in this example is also indicative of the third ' $i$ ' of hate speech, which is immediacy. Immediacy means that most hate writers act on the spur of the moment, writing the post or the comment spontaneously having been triggered by emotions, provocative posts written by others or news they feel strongly about. It is also interesting to note that most of these kinds of posts and comments are subsequently deleted by the post writers themselves.

Invectiveness is the fourth specific feature of hateful comments on Facebook among Armenian users. This relates to abusive expressions or discourse exercised by users to target a group defined by certain characteristics or an individual representing that group.

My analysis of invectives used by Facebook users shows that invectives are inherent in explicitly hateful comments, and can range from interjections indicating disgust and repulsion to derogatory and sometimes even taboo words. Interestingly, invectives very often appear in posts generated under an image or link to a video reflecting a thought-provoking event, the mere mention of which may suffice for the social media user to write a hateful comment about it.

In the Facebook comment in the next example targeting a politician representing the Republican Party of Armenia, the writer makes use of the Armenian interjection Yaaaakhk that denotes an expression of intense disgust towards someone or something.

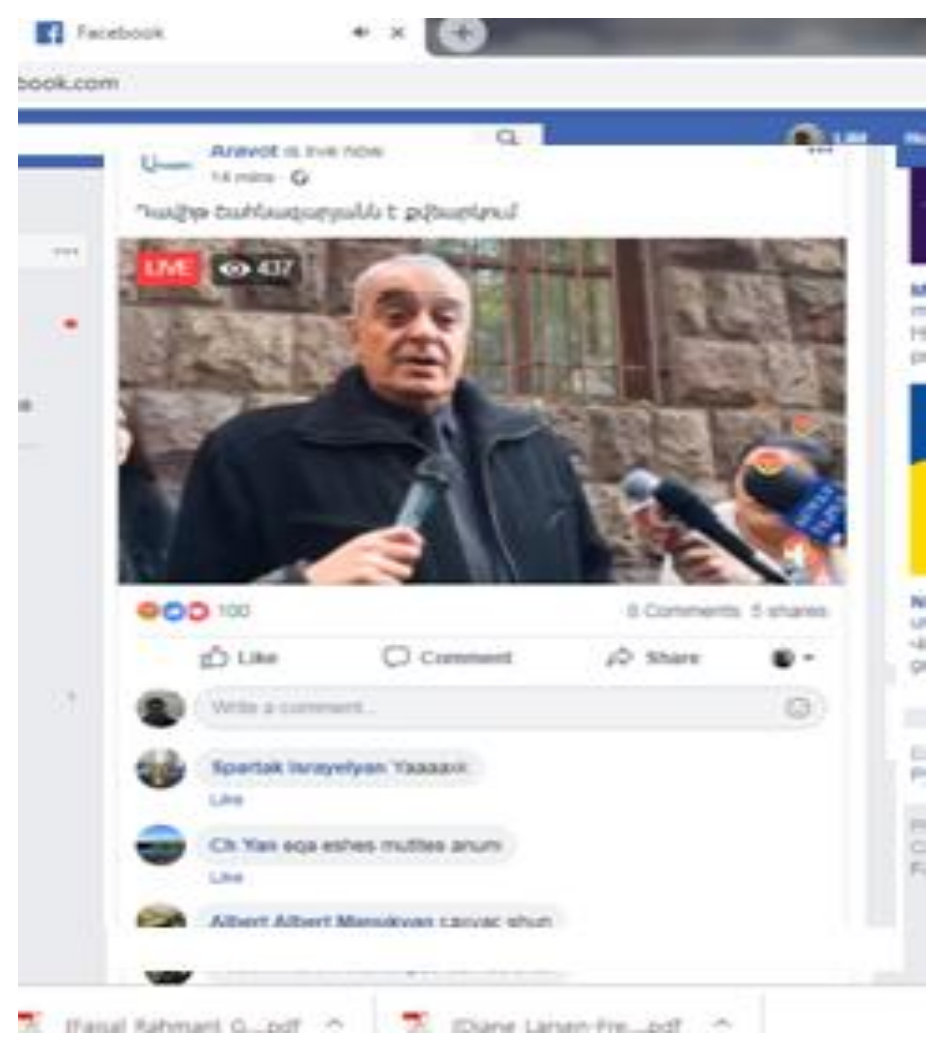

\section{Example $3^{19}$}

It is also interesting to note that some users attempt to intensify the emotions they express by using modifiers (e.g., adverbs), for instance 'I am so sick of you', /zzvacrir/, as used in one of the comments posted under the same image.

\footnotetext{
${ }^{19}$ From www.aravot.am. Accessed on 9 December 2018.
} 
As mentioned earlier, hate speech targets groups defined by certain characteristics. However, there are also frequent cases where people from certain occupations, for example, journalists or the media outlets themselves, become the target of hateful comments and posts, as seen in the following comment that was posted on the official page of 'Aravot', an online newspaper. Prior to the comment, the newspaper had shared a news story stating that the EU-Armenia agreement did not top the European partners' agenda. In response to this publication, a Facebook user posted a comment saying how sick she had become of Aravot's publications.

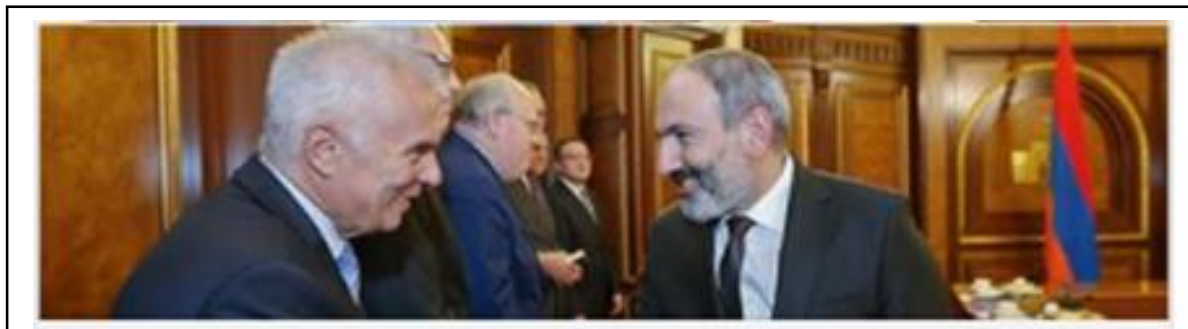

\section{ARANOT.AN}

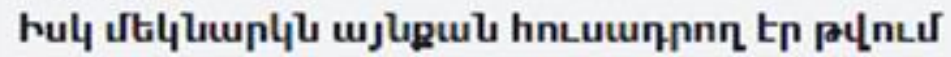

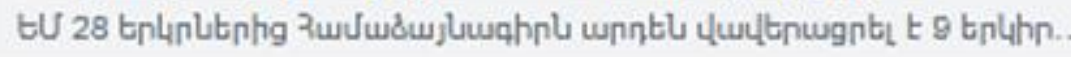

\section{$00 \div 9$}

2 comments

$\square$ Like $\square$ comment $\Rightarrow$ Share

Most relevant *

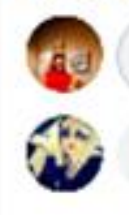

Write a comment...
Kristina Tina Aravot. Az. Arten zzvcreles
Uke - Reply - $23 \mathrm{~m}$

\section{English translation of the comment}

Aravot, hon, don't make us sick.

\section{Example $4^{20}$}

We can see Kristina Tina commenting on Aravot's post in a Latin transliteration of Armenian and building on alliteration. It is interesting to reflect on the use of 'az', which is the shortened form for the Armenian colloquial word [a'ziz]. The word is derived from Arabic and means 'dear' and 'precious'. In Armenian, it is very often used as an address form in informal communication. At the same time, the use of 'aziz' may imply a patronising attitude, as it also appears in exchanges marked by subordination and indicates the power one of the speakers exercises over the other. In her comment, Kristina Tina uses 'az' and 'zzvcrel es' (the expression for 'you make me sick') to build alliteration and to intensify the negative effect of her comment.

After analysing hateful posts and comments written by public figures on Facebook, I have noticed that there are also cases where Armenian users are less explicit and do not convey clear hate messages. Hate speech is very often context-bound, implying that the hatefulness of the comment depends on how the reader or the poster perceives it. In order to identify

\section{Ibid}


this kind of subtle or implicit message, it is important to consider the context in which the comments appear and assess the overall impact of the comment.

Let us consider the following example based on the post written by a contemporary Armenian blogger and writer on the eve of the snap elections dating back to 2018. The comment was retrieved from the poster's Facebook page. However, it was deleted a day later, as most readers found it offensive and discriminatory, hence the absence of the original screenshot.

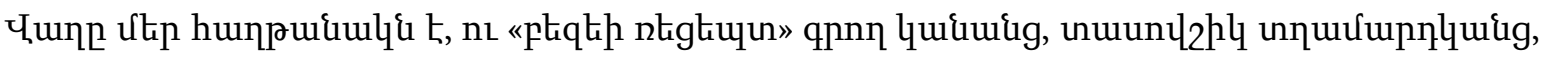
ưupunnıpjnı\{ณ:

\section{English translation of the post}

Tomorrow marks our victory, the defeat of the women who are into writing meringue recipes and the failure of male shufflers.

\section{Example 5}

Being an obvious proponent of the velvet revolution and the new government, the poster welcomes the new government that she hopes will be elected. She also says that the next day, making a clear reference to the day of the elections, we will win and others will lose. When naming the losers, she uses labels, applying short descriptive phrases such as 'women who write meringue recipes' and 'shufflers', making an implicit reference to the lower status of both groups in Armenian society.

By 'women who write meringue recipes', the poster makes reference to Armenian housewives; women who do not work and who dedicate most of their time and efforts to their families. Despite the high number of non-working women in Armenia, this phenomenon is occasionally criticised in our society, especially by women who support women's rights. The poster, who is a popular blogger in Armenia, appears to be one of them. It is interesting to note that through her selection of words, she also implicitly targets Armenian men, since in Armenia, if a woman does not work, it is most probably because her husband does not let her.

Although this post does not explicitly reflect hatred against the group of women who enjoy writing recipes, it is clearly characterised by generalisations, labelling and stereotyping. At the same time, it can be inferred from the post that under the previous government, women enjoyed such a low social level that their interests were restricted to writing meringue recipes. Obviously, this observation is based on exaggeration, as not every woman who is into writing meringue recipes is necessarily restricted in her interests and choice.

The readers themselves perceive the hatefulness of the post by taking into consideration the context and the negative connotation that the expressions 'women who write meringue recipes' and 'shufflers' acquire by being categorised under the group of losers. It is interesting to note that the word unuun $\bigcup_{2} \mathrm{hl}_{1}$ (shuffler) in Armenian slang denotes a person who is not strong-willed and who is bullied in the military. 
COVID-19 not only led to the explosion of xenophobia in the social media and replenished the English language with new types of critical language, such as 'covidiots'21 or 'doomscrolling'22, but it also created fertile ground for hate speakers both in Armenia and worldwide. It is interesting to note that the spread of the coronavirus in Armenia started with one single case of a woman who concealed her fever solely because she wanted to host her son's engagement party. The party took place in Ejmiatsin, a small town that at the start of the pandemic accounted for more than half of Armenia's confirmed coronavirus cases. The happy occasion turned out to be a misery for most of the party guests who ended up in hospital wards or in quarantine as potential coronavirus suspects, while the woman herself fell victim to the cascades of abusive and hostile language on Facebook.

The example provided below illustrates a Facebook post generated on the background of the first COVID-19 cases in Armenia back in March 2020 by one of the most popular radio hosts and reporters in Armenia. The post combines at least two features of online hate speech messages: immediacy, as it was obviously generated under the weight of emotions and was later deleted; and invectiveness, as it comprises offensive and derogatory words and harsh criticism of the woman's demeanour.

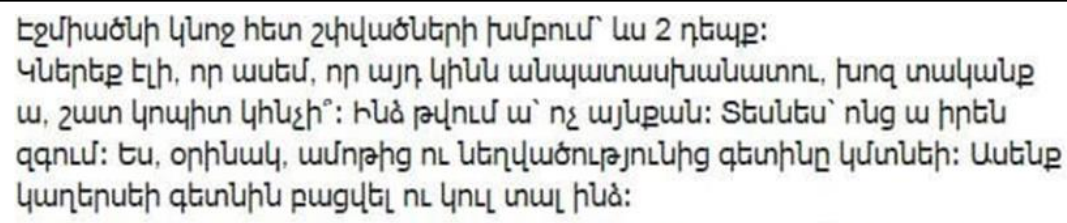

\section{English translation of the post}

There are two more cases among Ejmiatsin party guests who tested positive for coronavirus. If I call that woman an irresponsible swine and scum, will I be too harsh? I wonder what she's feeling now. If I were in her shoes, I'd rather the ground swallowed me up because of embarrassment and shame.

\section{Example $6^{23}$}

When analysing the language in the post, we can see that the writer firstly prepares the ground for the hostile language she is going to use by activating the mental schemata of her audience and introducing them to the context 'There are two more cases ...'. She then proceeds with an offensive rhetorical question by engaging the attention of her audience and verbally attacking the woman by establishing a kind of detachment between herself and her target through the use of the deictic marker 'that' ('that woman'/ uj n lhiqu). It is interesting to see that despite the hate speaker's use of the first conditional, her post explicitly conveys the hateful message because of the invectives it comprises ('scum' and 'swine') and the persuasive power of the rhetorical question ('If I call that woman an irresponsible swine and scum, will I be too harsh?'). Her indirectly formed polite question about how the woman is feeling is indicative of sarcasm and is entirely context-bound, since despite the fact that she knows the woman is suffering from the coronavirus, the poster does not seem worried about her health and merely wonders whether she regrets the repercussions of her irresponsible behaviour. She goes further by providing her answer to the same question: 'I'd rather the ground swallowed me up because of embarrassment and shame', implying that this is exactly how the woman in question should feel: 'embarrassed' and 'shameful'.

\footnotetext{
${ }^{21}$ Someone who stockpiles toilet paper and flouts physical distancing rules.

22 Obsessive consumption of depressing pandemic news.

${ }^{23}$ From https://www. facebook.com/lucy.kocharyan. Accessed on 20 March 2020.
} 


\section{Conclusions}

Unfortunately, despite the claims that it connects people, Facebook is not devoid of hateful comments or posts, which very often seek to provoke the reader or are generated in response to similar provocations.

Hate speech on Facebook obviously owes its origin to the offline-nurtured negative dispositions, stereotypes and convictions that push users to take advantage of the openness and sense of detachment social media can provide, and that shape their criticism of certain events, groups and people into hate speech messages.

Research into the contextual and language features of hate speech posts and comments has helped to identify the principle of the four 'i's: invisibility, incitement to violence, invectiveness and immediacy, as the main descriptors of online hate speech posts and comments. The discourse analysis performed on the same posts by Armenian Facebook users shows that the language of hate speech writers is characterised by an informal tone and mostly comprises offensive words, insulting labels, generalised statements, conditional sentences, passive voice, rhetorical and indirectly-formed questions, and deictic markers. 


\section{References}

Bekaryan, L. (2019) Ways of Expressing Hate Speech in the Social Media in Armenia. Yerevan: Misma LTD.

Benesch, S. (2012) Dangerous Speech: A Proposal to Prevent Group Violence. World Policy Institute

Citron, D.K. (2014) Hate Crimes in Cyberspace. Harvard University Press.

ElSherief, Mai \& Kulkarni, Vivek \& Nguyen, Dana \& Wang, William \& Belding, Elizabeth. (2018). Hate Lingo: A Target-based Linguistic Analysis of Hate Speech in Social Media.

Erjavec, K. \& Kovačič, M. Poler (2012) "You Don't Understand, This is a New War!" Analysis of Hate Speech in News Web Sites' Comments, Mass Communication and Society, 15:6, 899-920.

Silva, L., Mondal, M., Correa, D., Benevenuto, F., and Weber, I. (2016). Analyzing the targets of hate in online social media. In Proceedings of the 10th International Conference on Web and Social Media, ICWSM 2016, pages 687-690. AAAI Press.

Suler, J. (1996). The Psychology of Cyberspace. Rider University: Department of Psychology.

Van Dijk, T. (1984). Prejudice in Discourse: An Analysis of Ethnic Prejudice in Cognition and Conversation. Amsterdam: J. Benjamins Co. https://doi.org/10.1075/pb.v.3, Accessed on 24 April 2020.

Waldron, J. (2012). The Harm in Hate Speech. Cambridge, Mass.: Harvard University Press. Retrieved from: http://www.iconnectblog.com/2013/02/book-review-jeremy-waldronsthe-harm-in-hate-speech, Accessed on 25 April 2020

Wodak, R., \& Meyer, M. (Eds.) (2009). Methods of Critical Discourse Analysis. London: SAGE.

\section{Sources of Language Data}

https://www.facebook.com/hatespeecharmenia/. Accessed on 2 November 2018.

https://www.facebook.com/sunesevada. Accessed on 8 December 2018.

https://www.facebook.com/aravot.am Accessed on 9 December 2018.

https://www.facebook.com/Mardaser. Zaruhi Mejlumyan's Facebook page. Accessed on 17 January 2019.

https://www.facebook.com/lucy.kocharyan. Accessed on 20 March 2020. 